\title{
Core and Periphery in the European Monetary Union: Bayoumi and Eichengreen 25 years later
}

\author{
Nauro F. Campos ${ }^{\mathrm{a}, \mathrm{b}, \mathrm{c}, *}$, Corrado Macchiarelli ${ }^{\mathrm{a}, \mathrm{d}}$ \\ a Brunel University London, United Kingdom \\ ${ }^{\mathrm{b}}$ ETH, Zurich, Switzerland \\ ${ }^{\mathrm{c}}$ IZA, Bonn, Germany \\ ${ }^{\mathrm{d}}$ London School of Economics, United Kingdom
}

\section{H I G H L I G H T S}

- Bayoumi and Eichengreen (1993) raises concerns about a core-periphery divide pre-EMU.

- Using same estimation method, window and sample, we update their study post-EMU.

- This paper also proposes a new over-identifying restriction core-periphery test.

- The test is used to objectively classify countries into core and periphery.

- We find that the EMU weakened the original core-periphery pattern.

\section{A R T I C L E I N F O}

\section{Article history:}

Received 30 March 2016

Received in revised form

27 July 2016

Accepted 30 July 2016

Available online 6 August 2016

\section{JEL classification:}

E32

E63

F02

\section{Keywords:}

Business cycle synchronization

Structural VAR

European Monetary Union

Core-periphery

\section{G R A P H I C A L A B S T R A C T}

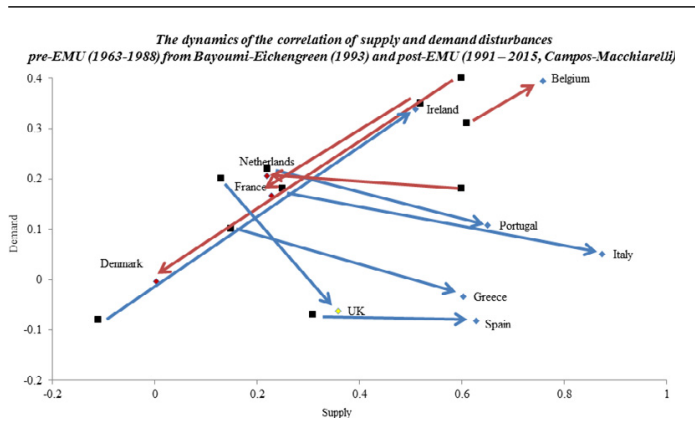

\section{A B S T R A C T}

Bayoumi and Eichengreen (1993) establish a EMU core-periphery pattern using 1963-1988 data. We use same methodology, sample, window length (1989-2015), and a novel over-identifying restriction test to ask whether the EMU strengthened or weakened the core-periphery pattern. Our results suggest the latter.

(C) 2016 The Authors. Published by Elsevier B.V. This is an open access article under the CC BY license (http://creativecommons.org/licenses/by/4.0/).

\footnotetext{
We would like to thank, without implicating, Paul De Grauwe, Jarko Fidrmuc, Maurizio Habib, Ayhan Kose, an anonymous referee and seminar participants at NIESR London, Brunel University London, 12th BMRC Annual Conference, European Central Bank and The World Bank for valuable comments on previous versions of this paper.

* Correspondence to: Department of Economics, Brunel University London, Uxbridge UB8 3PH, United Kingdom.

E-mail address: nauro.campos@brunel.ac.uk (N.F. Campos).
}

\section{Introduction}

The seminal paper by Bayoumi and Eichengreen (1993) highlights the existence of a core-periphery pattern in the runup to the European Monetary Union (EMU). If persistent, this pattern would be detrimental to the EMU project. Using pre-EMU data to estimate the degree of supply shocks synchronization, they argue that there is a core (Germany, France, Belgium, Netherlands and Denmark) where shocks are highly correlated and 
a periphery (Greece, Ireland, Italy, Portugal, Spain and UK) where synchronization is significantly lower.

The objective of this paper is to revisit Bayoumi and Eichengreen (1993) in order to evaluate the effect of the EMU on the core-periphery pattern they find using 1963-1988 data. We use the same estimation methodology, sample, and time window (25 years) to replicate their results for 1989-2015. We ask whether the EMU strengthened or weakened the core-periphery pattern. Based on a new over-identifying restriction test, our results suggest that the core-periphery pattern has actually weakened.

\section{Theory}

The main research question driving the scholarship on optimal currency areas (OCA) regards the costs and benefits of sharing a currency (Alesina and Barro, 2002). The main cost is the loss of monetary policy autonomy, while the main benefits are transaction costs and exchange rate uncertainty reductions, and increasing price transparency, trade and competition. OCA theory stresses labour mobility, product diversification and trade openness as criteria while debating the endogeneity of currency unions (Frankel and Rose, 1998). Recent work highlights the role of credibility shocks: with varying degrees of commitment (time inconsistency), countries with dissimilar credibility shocks should join currency unions (Chari et al., 2015). A second relevant recent strand highlights situations in which OCA criteria are modelled as interdependent. For instance, Farhi and Werning (2015) focus on interactions between openness and mobility. Recent econometric evidence showing the absence of a robust effect of currency unions on trade raises caveats to the discussion above (Glick and Rose, 2016).

\section{Estimation}

The methodology used by Bayoumi and Eichengreen (1993) is an extension of the Blanchard and Quah (1989) procedure for decomposing permanent and temporary shocks. Consider a system where the true model is represented by an infinite moving average of a (vector) of variables, $X_{t}$, and shocks, $\epsilon_{t}$. Using the lag operator $L$, a bi-variate VAR featuring real GDP and its deflator can be written as an infinite moving average representation of demand and supply disturbances:

$X_{t}=A_{0} \epsilon_{t}+A_{1} \epsilon_{t-1}+A_{2} \epsilon_{t-2}+A_{3} \epsilon_{t-3}+\cdots=\sum_{i=0}^{\infty} L^{i} A_{i} \epsilon_{t}$

where $X_{t}=\left[\Delta y_{t}, \Delta p_{t}\right]$ and the matrices $A$ represent the impulse response functions of the shocks to the elements of $X$. It follows that

$\left[\begin{array}{l}\Delta y_{t} \\ \Delta p_{t}\end{array}\right]=\sum_{i=0}^{\infty} L^{i}\left[\begin{array}{ll}a_{11 i} & a_{12 i} \\ a_{21 i} & a_{22 i}\end{array}\right]\left[\begin{array}{l}\epsilon_{d t} \\ \epsilon_{s t}\end{array}\right]$

where $y_{t}$ and $p_{t}$ represent the logarithm of output and prices and $\epsilon_{t}$ are i.i.d. disturbances, which identify supply and demand shocks (Ramey, forthcoming). For the $i$ th country, $a_{11 i}$ represents element $a_{11}$, in matrix $A_{i}$ and so on.

This framework implies that supply shocks have permanent effects on output, while demand shocks have temporary effects. Both have permanent (opposite) effects on prices. The cumulative effect of demand shocks on the change in output must be zero:

$\sum_{i=0}^{\infty} a_{11 i}=0$

Using the standard relation between the VAR's residuals $\left(e_{t}\right)$ and demand and supply shocks, i.e. $e_{t}=C \epsilon_{t}$ for each country, exact identification of the $C$ matrix requires four restrictions. Two are normalizations, which define the variance of the shocks $\epsilon_{d t}$ and $\epsilon_{s t}$. The third restriction is from assuming that demand and supply shocks are orthogonal to each other. The fourth that demand shocks have only temporary effects on output (Eq. (3)).

Based on the standard AD-AS model, there is one restriction that Bayoumi and Eichengreen (1993) do not impose as their model was exactly identified. Here we extend their framework by imposing a fifth, additional over-identifying restriction and we explicitly test for a permanent effect of supply shocks on output by imposing $\sum_{i=0}^{\infty} a_{12 i}=\gamma$, where $\gamma>0$. Accordingly, demand in each country is restricted to respond to supply shocks qualitatively (sign) and quantitatively (size) in the same way. In terms of the structural VAR analysis, this implies:

$$
\sum_{i=1}^{\infty}\left[\begin{array}{ll}
d_{11 i} & d_{12 i} \\
d_{21 i} & d_{22 i}
\end{array}\right]\left[\begin{array}{ll}
c_{11} & c_{12} \\
c_{21} & c_{22}
\end{array}\right]=\left[\begin{array}{ll}
0 & \gamma \\
\cdot & \cdot
\end{array}\right] .
$$

We do not restrict $\gamma$ a priori; instead, we vary $\gamma$ in the interval $[0.1,2]$ and choose its value optimally, as explained below (the number we chose to report is $\gamma=1$.)

\subsection{Testing for over-identifying restriction}

In order to test for the over-identifying restriction described above, we estimate Bayoumi and Eichengreen (1993) SVAR model. Differently from them, we bootstrap the original VAR residuals in a i.i.d. fashion and generate $K=10.000$ data sets. For each of the $k$ th samples we test for the over-identifying restriction based on a LR-test. We record the number of rejections (NoR) of the over-identifying restriction test at each bootstrap replication, and calculate

$N_{i} R_{i}=100 \times \frac{\sum_{k=1}^{K}\left\{N o R=1 \mid-2\left(L_{r}-L_{u}\right)>\chi_{q-\left(\frac{n^{2}-n}{2}\right)}^{2}\right\}_{i, k}}{K}$

where $L_{u}$ and $L_{r}$ are the maximized values of the (Gaussian) log likelihood function of the unrestricted and restricted regressions, respectively. Under $H_{0}$, the LR statistic has an asymptotic distribution with degrees of freedom equal to the number of long-run restrictions $(q)$ minus $\left(n^{2}-n\right) / 2$, where $n$ is the VARdimension (in this case $n=2$ ). We calculate $N o R_{i}$ for different values of $\gamma$.

Based on the results in Table 2A (cf. Appendix A), we chose the value of $\gamma$ which minimizes the total number of rejections in our sample. Demand and supply shocks are then retrieved by bootstrap, specifically by recalculating the VAR parameters $(K=$ 10.000 ), identifying the SVAR and considering median values of structural disturbances under $\gamma=1$.

\section{Results}

Fig. 1 shows our main results. The residuals (median bootstrapped) are retrieved from a Structural VAR with two lags for all countries, no constant, and using yearly data with respect to Germany closely following Bayoumi and Eichengreen (1993). The over-identifying restriction is imposed and the sample is 1989-2015. As dispersion has decreased compared to the pre-EMU era, we argue the results suggest the core-periphery pattern has weakened after 1989.

Based on the bootstrapped VAR, we test for the over-identifying restriction described above where (non) rejection supports classifying the country as periphery (centre). The four countries for which the rejection of the over-identifying restriction is stronger, at conventional significance levels, are Ireland, Spain, Greece and Portugal (Table $2 \mathrm{~A}$ in the Appendix A). ${ }^{1}$ Without imposing this over-identifying restriction for these four countries, the

\footnotetext{
1 The UK shows an ambiguous development: higher correlation of supply shocks but lower correlation of demand shocks.
} 


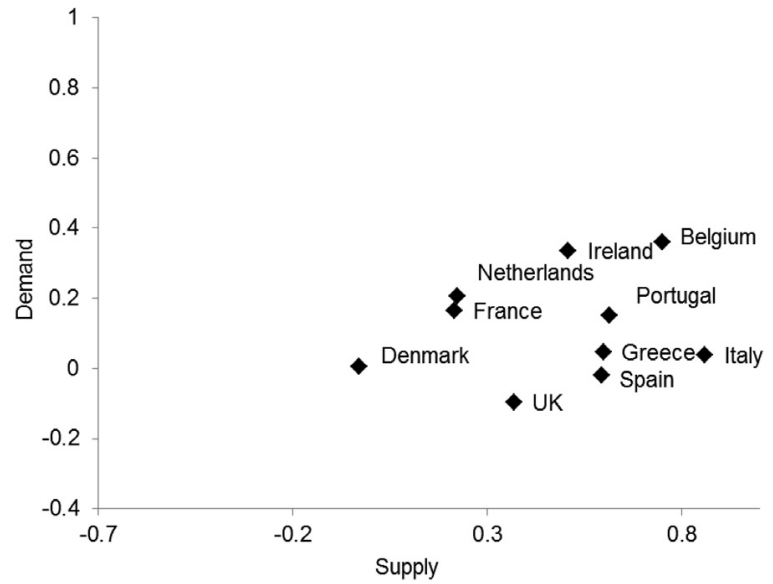

Fig. 1. Correlation of supply and demand disturbances imposing the overidentifying restriction (bootstrapped residuals-median values). Note: This figure reports median bootstrapped residuals based on 10.000 VAR replications. Structural residuals are retrieved from a SVAR where the over-identifying restriction above is imposed for all countries. The sample for this SVAR is 1989-2015, with two lags for all countries and no constant as in Bayoumi and Eichengreen (1993). The demand and supply disturbances correlation coefficients vis-vis Germany are reported in Appendix A Table 3A.

core-periphery pattern in Bayoumi and Eichengreen's terms actually weakens even further. When the over-identifying restriction is not imposed, Ireland and Portugal move down the demand-axis and Greece and Spain jump to the left (Fig. 2).

Overall, our results support a re-interpretation of the coreperiphery pattern: after EMU a new, smaller periphery emerges (Spain, Portugal, Ireland and Greece) and its dynamics is systematically different from the rest in that, for these countries, the overidentifying restriction is rejected by the data in most cases.

One important concern is that the relationship between demand and supply may have changed over time and/or the nature of shocks has been altered by the EMU itself. Hence, a structural identification on economic variables that may have changed can be misleading. One can argue that the increase in correlation in supply disturbances may be due to a larger role for oil price shocks in the sample. Proponents of using the nominal price of oil in empirical models of the transmission of oil price shocks tend to conclude that there is no stable dynamic relationship between percent changes in the nominal price of oil and inflation. There is evidence from

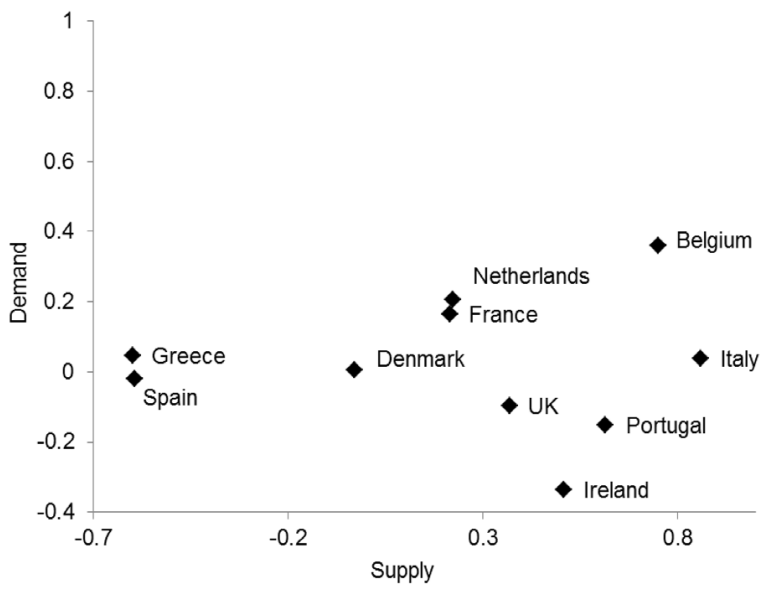

Fig. 2. Correlation of supply and demand disturbances (bootstrapped residualsmedian values) relaxing the over-identifying restriction. Note: This figure reports median bootstrapped residuals based on 10.000 VAR replications. Structural residuals are retrieved from a SVAR where the over-identifying restriction above is imposed for all countries, with the exception of Ireland, Spain, Greece and Portugal. The sample for this SVAR is 1989-2015, with two lags for all countries and no constant as in Bayoumi and Eichengreen (1993). The demand and supply disturbances correlation coefficients are reported in Appendix A Table 4A.

in-sample fitting exercises, however, of a predictive relationship between suitable nonlinear transformations of the nominal price of oil and real output. The most successful of these transformations is the Net Oil Price Increase (NOPI) measure from Hamilton (2003). Let $s_{t}$ denote the nominal price of oil in logs, then

NOPI $_{t}=\left\{\begin{array}{l}s_{t}-\max \left(s_{t-1}, s_{t-37}\right) \\ \text { if } s_{t}-\max \left(s_{t-1}, s_{t-37}\right)>0 \\ 0 \quad \text { otherwise. }\end{array}\right.$

The net oil price increase is a censored predictor that assigns zero weight to net oil price decreases and singles out oil prices peaks in a 36-month (or shorter) window. To construct a Net Oil Price Index, we use the Brent Europe crude oil price index at a monthly frequency and identify the net increases (Fig. 3). Based on this characterization, we define dummy variables at a yearly frequency. In particular, we identify the following net oil increases $\{1996,1999,2000,2004-2008\}$. When conditioning the VAR on the NOPI, we find little evidence that this is relevant in this framework and that the responses of real GDP and inflation

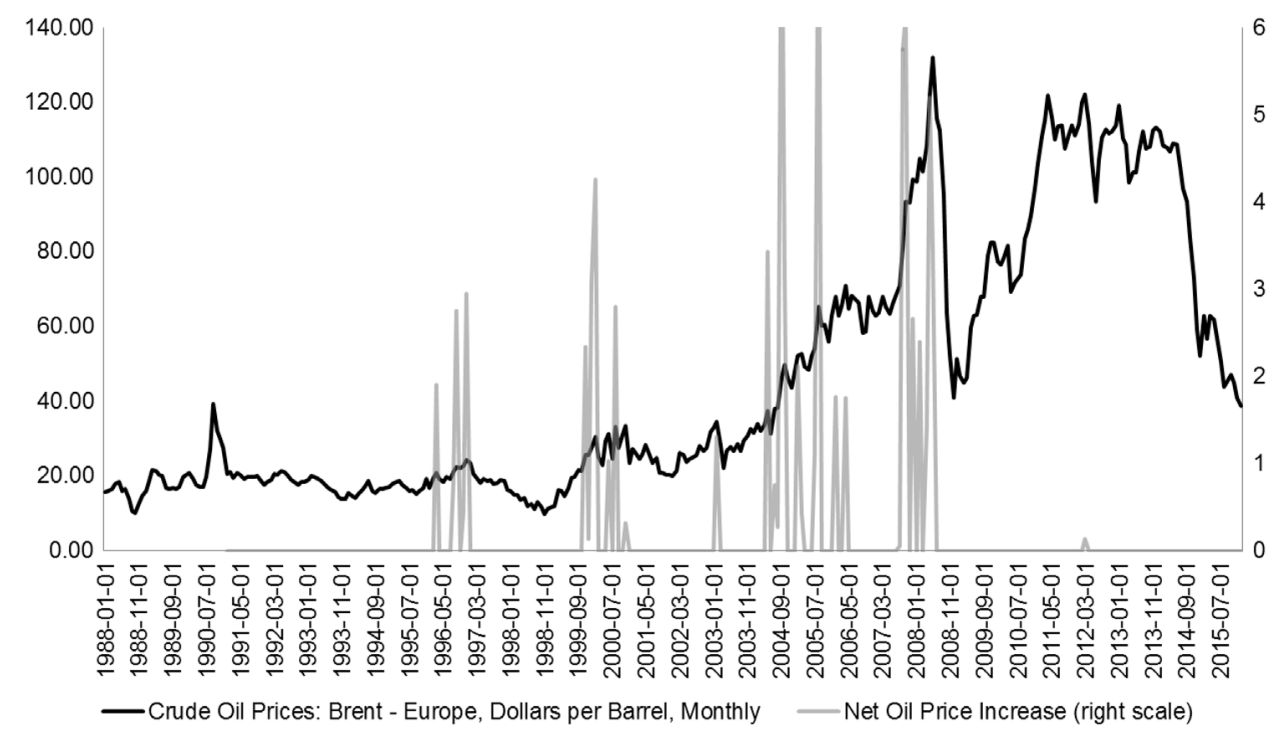

Fig. 3. Net oil price increases indicator. 


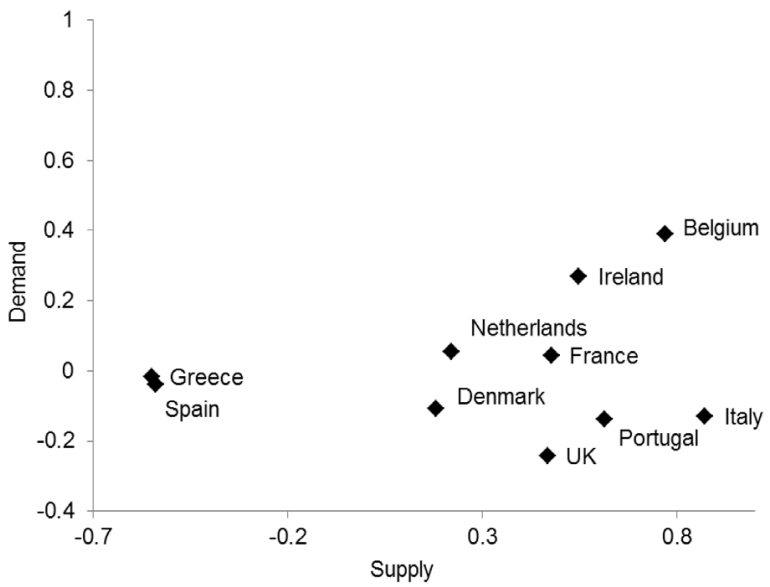

Fig. 4. Correlation of supply and demand disturbances relaxing the overidentifying restriction and conditional on NOPI (bootstrapped residuals-median values). Note: This figure reports median bootstrapped residuals based on 10.000 VAR replications. Structural residuals are retrieved from a SVAR where the overidentifying restriction above is imposed for all countries, with the exception of Ireland, Spain, Greece and Portugal. The sample for this SVAR is 1989-2015, with two lags for all countries and no constant as in Bayoumi and Eichengreen (1993). The SVAR is conditional on NOPI dummies (cf. Results' section).

to demand and supply innovations are driven by net oil price increases (results also remain broadly unchanged if we use the change in the price of oil as exogenous variable instead) (see Fig. 4).

\section{Conclusions}

Bayoumi and Eichengreen (1993) is a seminal paper because, inter alia, it is one of the first to point out the risks of an entrenched core-periphery to the then nascent EMU. Their influential diagnostics was based upon data covering 25 years from 1963 to 1988. Using the same methodology, sample, and time window, this paper replicates their results for 1989-2015. We ask whether the EMU strengthened or weakened the core-periphery pattern. Using a new over-identifying restriction test, our results suggest the EMU has significantly weakened the original pattern described in Bayoumi and Eichengreen, in that we find, based on demand and supply shocks, changes in the clustering of countries.

\section{Appendix A. Supplementary data}

Supplementary material related to this article can be found online at http://dx.doi.org/10.1016/j.econlet.2016.07.040.

\section{References}

Alesina, A., Barro, R., 2002. Currency unions. Quart. J. Econ. 117 (2), 409-436. Bayoumi, T., Eichengreen, B., 1993. Shocking aspects of European monetary integration. In: Torres, F., Giavazzi, F. (Eds.), Adjustment and Growth in the European Monetary Union. Cambridge University Press.

Blanchard, O., Quah, D., 1989. The dynamic effects of aggregate demand and aggregate supply disturbances. Amer. Econ. Rev. 79, 655-673. 1989.

Chari, V.V., Dovis, A., Kehoe, P., 2015. Rethinking optimal currency areas. Federal Reserve Bank of Minneapolis, Research Department Staff Report.

Farhi, E., Werning, I., 2015. Labor mobility in currency unions. MIT Mimeo.

Frankel, J., Rose, A., 1998. The endogeneity of the optimum currency area criteria. Econ. J. 108 (449), 1009-1025.

Glick, R., Rose, A., 2016. Currency unions and trade: A post-EMU Mea Culpa, Mimeo. Hamilton, J., 2003. What is an oil shock? J. Econometrics 113, 363-398.

Ramey, V., 2016. Macroeconomic shocks and their propagation. In: Taylor, J., Uhlig, H. (Eds.), Handbook of Macroeconomics, Volume 2. Elsevier, (forthcoming). 